\title{
Comparative study of Puricelli's panorametry in conventional panoramic radiography and cone beam computed tomography panoramic reconstruction
}

\section{Estudo comparativo da panorametria de Puricelli em radiografia panorâmica convencional e reconstrução panorâmica de tomografia computadorizada de feixe cônico}

\author{
Edela Puricelli* \\ Gustavo Lisboa Martins** \\ Deise Ponzoni** \\ Adriana Corsetti**** \\ Renan Langie (**** $^{* *}$ \\ Mario Alexandre Morganti*
}

\begin{abstract}
Objectives: to compare the reproducibility of Puricelli's panorametry on conventional panoramic radiography and on CBCT reformatted panoramic images, acquired in MIP mode. This study also compared linear and angular measurements between both exams. Methods: were evaluated 54 pairs of conventional panoramic radiography and CBCT panoramic MIP reconstructions. panorametry was manually traced, in both films, by three examiners. The originally proposed linear and angular, dental and skeletal measurements where tabulated and compared between imaging methods. Inter-examiner reproducibility was tested by intraclass correlation coefficient, and the differences between measurements of both methods were analyzed by Student's $t$ test. Results: the inter-examiner correlation was high for both the conventional panoramic radiography and CBCT panoramic MIP reconstructions $(0.86 \pm 0.07$ and $0.88 \pm 0.07$, respectively). Total magnification of pano-
\end{abstract}

ramic radiograph, for the studied measurements, was of $4.3 \%$, being vertically higher (12\%) and to the horizontal inferior line (11.5\%) comparing to the angular measurements of straight lines $(6.7 \%)$ and to the horizontal superior lines (1.9\%). The conventional panoramic radiography, in comparison to the CBCT, presented lower values for most angular measurements. Conclusions: Puricelli's panorametry presents a high degree of reproducibility in both conventional panoramic radiography and CBCT reformatted panoramic images. Conventional panoramic radiography presents augmented linear and angular skeletal measurements and reduced dental angular measurements when compared to CBCT reformatted panoramic images. Conventional panoramic radiographs seem to present a consistent augmentation of the right side of the mandibular image.

Keywords: Cone-beam computed tomography. Panoramic radiography. Mandible.

PhD in Oral and Maxillofacial Surgery, Universidade Federal do Rio Grande do Sul. Professor and Head of Oral and Maxillofacial Department: Hospital de Clínicas de Porto Alegre and Santa Casa de Misericórdia Dental Center, Porto Alegre, RS, Brazil.

PhD in Oral and Maxillofacial Surgery, Universidade Federal do Rio Grande do Sul. Surgeon of Oral and Maxillofacial Department, Santa Casa de Misericórdia Dental Center, Porto Alegre, RS, Brazil.

$\mathrm{PhD}$ in Oral and Maxillofacial Surgery, Universidade Federal do Rio Grande do Sul. Professor of School of Dentistry, Universidade Federal do Rio Grande do Sul, Porto Alegre, RS, Brazil.

**** PhD in Oral and Maxillofacial Surgery, Universidade Federal do Rio Grande do Sul. Surgeon of Oral and Maxillofacial Department, Santa Casa de Misericordia Dental Center, Porto Alegre, RS, Brazil.

Master in Oral and Maxillofacial Surgery, Universidade Federal do Rio Grande do Sul. PhD student, School of Dentistry, Universidade Federal do Rio Grande do Sul, Porto Alegre, RS, Brazil.

${ }^{* * * * * *}$ Master in Orthodontics and Dentofacial Orthopedics, Pontifícia Universidade Católica do Rio Grande do Sul. PhD student, School of Dentistry, Universidade Federal do Rio Grande do Sul. Head of Orthodontist of the Department of Dentistry, Santa Casa de Misericórdia Dental Center, Porto Alegre, RS, Brazil. 


\section{Introduction}

Conventional panoramic radiography (orthopantomography) is an unquestionable and essential tool for diagnosis, treatment, and follow-up in Oral and Maxillofacial Surgery and Orthodontics. Despite its distortions and magnifications, this exam presents a unique possibility of appreciation of all skeletal and dental structures, bilaterally, without significant image superposition mainly at the mandibular body and ramus ${ }^{1}$. The radiation dose delivered by this technique is minimal, especially when compared to CT Scans and cone beam computed tomography (CBCT).

However, several studies have described the always-present distortion and magnification on panoramic radiography, as well as the limitations of this technique ${ }^{1,3-4}$. Moreover, attempts to develop standardized measurement methods based on panoramic radiography have usually stumbled on poor inter-examiner reproducibility ${ }^{5-8}$. The introduction of CBCT scan in Oral and Maxillofacial imaging with the development of modern hardware and software, has unfolded the possibility of a panoramic reformation in maximum intensity projection (MIP) mode. This technique is currently used for daily practice with software such as Xoran CAT ${ }^{\mathrm{TM}}$ (Xoran Technologies, Ann Harbor, MI, USA) and Dolphin $^{\mathrm{TM}}$ (Imaging Sciences, PA) widely adopted worldwide for dentofacial planning. Graphimetric methods for panoramic radiography have been proposed by several authors and compared to different controls, including dry skulls, models, images and patients $^{3,4,9-11}$. However, no studies could be found comparing conventional panoramic radiography to CBCT reformatted panoramic imaging.

The primary goal of this study is to compare the application and reproducibility of Puricelli's panorametry ${ }^{1}$ in conventional panoramic radiography and CBCT reformatted panoramic images. The study also aimed to analyze the differences in metric and angular measurements between both imaging methods, which would indicate different degrees of distortion.

\section{Methods}

Fifty-four pairs of conventional panoramic radiography and panoramic reformatted CBCT scans, from 54 different patients, 25 male and 29 female, median age 28.6 (18-51) years old, were selected for this study. Patient records were randomly selected from Puricelli Institute and from the Dental Department of Irmandade Santa Casa de Misericórdia of Porto Alegre. A conventional panoramic radiography and a complete CBCT scan, taken 7 days apart at the same imaging facility, were the inclusion criteria. Exclusion criteria were the presence of orthodontic appliances, complex skeletal altera- tions, relevant skeletal asymmetries, bone tumors, previous orthognathic surgery, and absence of one or both first inferior molar teeth.

The panoramic images were taken in the Orthophos CD ${ }^{\mathrm{TM}}$ (Sirona Dental Systems Inc., Italy). The CBCT scans were taken on the iCAT $^{\mathrm{TM}}$ (Imaging Sciences International, Hatfield, PA, USA), 14 bit grayscale, with a $16 \times 13 \mathrm{~cm}$ field of vision and 0.25 voxels. The CBCT images were reformatted in the MIP panoramic mode using the software Xoran CAT $^{\mathrm{TM}}$ (Xoran Technologies, Ann Harbor, MI, USA), through the software cfocal troughs were created. Therefore, 2 groups were formed: Group 1 - conventional panoramic radiography and Group 2 - CBCT reformatted panoramic.

Three examiners (post-graduate students) manually traced the Puricelli's panorametry in all 108 images, using selected measurements of the graphimetric proposal ${ }^{1,12}$. Tracing involved the following sequence, applied on both sides of the images: Structural Drawing of the Mandible; Horizontal Reference Plane (HRP) (Cartesian); Vertical Reference Plane (VRP) (Cartesian); Bisector of Horizontal and Vertical Reference Planes - Line 1 (Cartesian); Bisector Point (BP); Condylar Point (CP); Median Line of the Mandible (ML); Mental Foramen (MF); Line 2 (CP-MF); Median Point on the Gonial Area (MPGo); Line 3 (MF-MPGo); Line 4 (MPGo-CP); Structural Drawing of First Inferior Molar Teeth; Marking the Most External Points on the tooth crown equator; and tracing of the Long Axis (AX) of the tooth crown structure. All measurements (linear and angular), both sides considered, composed a total amount of 56 variables for each group per examiner (total 102 examinations per examiner). A pilot study for calibration was applied with highly satisfactory reproducibility. The final aspect of the Puricelli's panorametry is presented in the panoramic radiograph (Figure 1) and CBCT reformatted panoramic (Figure 2).

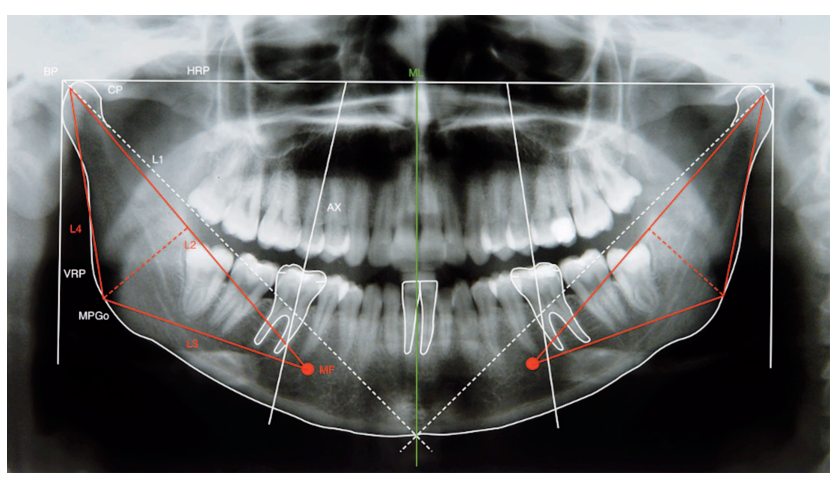

Figure 1 - Final aspect of the Puricelli panorametry on the conventional panoramic radiography used in this study. The reference points, lines and planes used were, in order by which they were traced: Horizontal Reference Plane (HRP); Vertical Reference Plane (VRP); Line 1 (L1); Bisector Point (BP); Condilar Point $(C P)$; Median Line of the Mandible $(\mathrm{ML})$; Mental Foramen (MF); Line 2 (L2); Median Point of the Gonial Area (MPGo); Line 3 (L3); Line 4 (L4); and Long Axis of Mandibular First Molars (AX) 


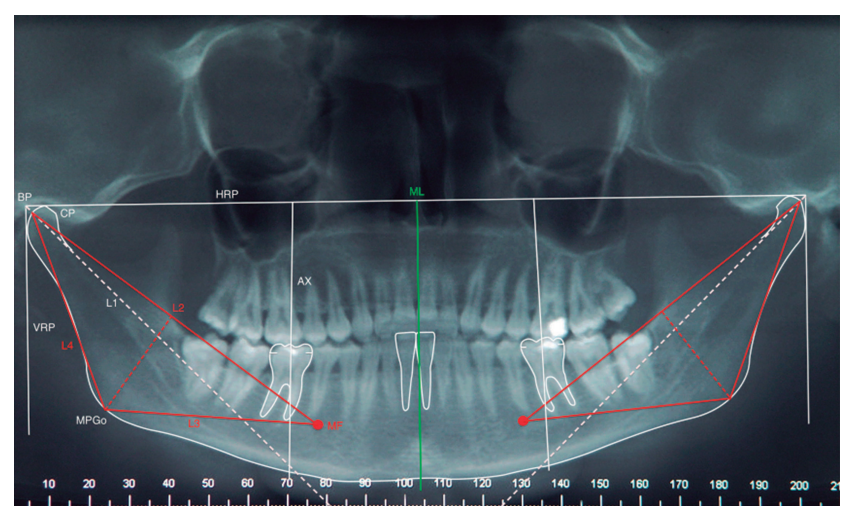

Figure 2 - Final aspect of the Puricelli panorametry on the CBCT reformatted panoramic used in this study. Reference points, lines and planes were the same as those used for the conventional panoramic radiography

The percentage of magnification on the panoramic radiograph, in relation to the $\mathrm{CBCT}$ reformatted panoramic image was calculated by applying the following formula to every pair of measurements and tabulating the results:

It was not possible to blind the examiners, considering the marked characteristics of the images. Linear and angular measurements were statistically analyzed between examiners and between groups using the Intraclass Correlation Coefficient (ICC) and the Student $t$ test ( $p>0,05$ ).

This research was approved by the Ethics Committee of the Universidade Federal do Rio Grande do Sul, School of Dentistry, and is in accordance with the Helsinki Declaration.

\section{Results}

The inter-examiner reproducibility was evaluated by the ICC, which revealed high levels of correlation in group 1 and group $2(0.86 \pm 0.07$ and $0.88 \pm 0.07$, respectively). Considering all linear and angular measurements, the mean magnification of the conventional panoramic radiography in relation to the CBCT reformatted panoramic was $4.3 \%$ $(-10.1$ - 31.4). Table 1 describes the grouped measurements, summarizing all variables. The right side presents measurements larger than the left side for almost all measurements where a statistically significant difference was observed. Table 2 reveals the measurement differences considering both sides and both imaging methods. No differences could be observed when comparing the right and left sides of the CBCT reformatted panoramic. On the other hand, all measures, except for L1-L4, were statistically different in both sides of the panoramic radiography. The panoramic radiography was magnified in relation to CBCT reformatted panoramic in all skeletal measures $(\mathrm{p}>0.05)$, with the exception of L2 and L1-L4.
Table 1 - Magnification percentage grouped into triangle lines, line angles, triangle angles, teeth angles and all angles

\begin{tabular}{l|c|c|c}
\hline \multirow{2}{*}{\multicolumn{1}{c|}{ Measure }} & \multicolumn{3}{|c}{ Magnification \%* } \\
\cline { 2 - 4 } & Right side & Left side & Total \\
\hline Triangle lines & 13.2 & 11.2 & 12.2 \\
Line angles & 6.8 & 6.6 & 6.7 \\
Triangle angles & -0.6 & -1.6 & -1.1 \\
Teeth angles & -3.4 & -5.1 & -4.3 \\
All angles & 1.7 & 0.7 & 1.2 \\
Total & 4.9 & 3.7 & 4.3 \\
\hline
\end{tabular}

*Panoramic radiograph in relation to CBCT reformatted panoramic.

Table 2 - Mean and Confidence Interval (Cl) of the differences in linear $(\mathrm{mm})$ and angular (degrees) measurements between right and left side of both methods

\begin{tabular}{l|c|c|c|c}
\hline \multirow{2}{*}{ Measure } & \multicolumn{2}{|c|}{ Panoramic radiograph } & \multicolumn{2}{c}{$\begin{array}{c}\text { CBCT reformatted } \\
\text { panoramic }\end{array}$} \\
\cline { 2 - 5 } & Mean & Cl 95\% & Mean & Cl 95\% \\
\hline L2 & $1.46 \neq$ & $0.29-2.64$ & 0.70 & $-0.17-1.58$ \\
L3* & $1.32 \neq$ & $0.11-2.19$ & 0.19 & $-0.62-0.99$ \\
L4* & $1.78 \neq$ & $0.95-2.61$ & 0.43 & $-0.24-1.09$ \\
L2-L3* & $0.70 \neq$ & $0.15-1.25$ & -0.09 & $-0.56-0.37$ \\
L3-L4* & $-1.56 \neq$ & $-2.54--0.57$ & 0.30 & $-0.57-1.16$ \\
L4-L2* & $0.80 \neq$ & $0.26-1.34$ & 0.06 & $-0.49-0.61$ \\
L1-L4 & -0.06 & $-0.83-0.72$ & 0.44 & $-0.50-1.39$ \\
\hline
\end{tabular}

* Statistical difference between methods $(p<0.05)$

₹ Statistical difference between right and left sides for each method $(p<0.05)$.

Table 3 presents the magnification percentage for the higher metrical amplitudes of the images, considering the higher upper horizontal measure (Horizontal Reference Plane), the higher lower horizontal measure (rMPGo-lMPGo), the higher diagonal measure (L1) and the higher vertical measure (L4) of all variables. These data revealed inconsistent magnification when considering different areas of the image.

Table 3 - Magnification percentage of the larger metrical amplitudes

\begin{tabular}{l|c|c|c}
\hline \multirow{2}{*}{ Measure } & \multicolumn{3}{|c}{ Magnification \%* } \\
\cline { 2 - 4 } & Right side & Left side & Total \\
\hline $\begin{array}{l}\text { Horizontal Reference } \\
\text { Plane }\end{array}$ & - & - & 1.9 \\
rMPGo-IMPGo & - & - & 11.5 \\
L1 & 2.8 & 2.0 & 2.4 \\
L4 & 13.7 & 10.4 & 12.0 \\
\hline
\end{tabular}

*Panoramic radiograph in relation to $\mathrm{CBCT}$ reformatted panoramic.

Table 4 presents teeth angular measures, comparing both sides and both methods. In the conventional panoramic radiography all measurements were higher on the right side, except for the angle between the first molar and L3, which showed no difference. On the other hand, in CBCT reformatted panoramic, only the angle between the first molar and L3 was statistically different, with left side measurements being higher than those on the right side. Comparing both techniques, statistically significant differences could be observed in all teeth angular measurements, with lower values for the conventional panoramic radiography. 
Table 4 - Means ( \pm standard deviation) of angular measurements referent to first molars in right and left sides in both techniques (p>0.05)

\begin{tabular}{l|c|c|c|c}
\hline \multirow{2}{*}{\multicolumn{1}{c|}{ Measure }} & \multicolumn{2}{|c|}{ Conventional panoramic radiography } & \multicolumn{2}{c}{ CBCT reformatted panoramic } \\
\cline { 2 - 5 } & Right side & Left side & Right side & Left side \\
\hline Molar- CD-CE & $81.01 \pm 5.02 \mathrm{Aa}$ & $78.17 \pm 6.96 \mathrm{Ba}$ & $87.88 \pm 5.26 \mathrm{Ab}$ & $86.98 \pm 6.41 \mathrm{Ab}$ \\
Molar-L1 & $125.71 \pm 5.00 \mathrm{Aa}$ & $120.79 \pm 17.71 \mathrm{Ba}$ & $132.36 \pm 5.63 \mathrm{Ab}$ & $131.42 \pm 6.02 \mathrm{Ab}$ \\
Molar-L2 & $129.94 \pm 4.22 \mathrm{Aa}$ & $128.32 \pm 6.46 \mathrm{Ba}$ & $127.63 \pm 4.41 \mathrm{Ab}$ & $128.33 \pm 6.46 \mathrm{Ab}$ \\
Molar-L3 & $83.08 \pm 4.97 \mathrm{Aa}$ & $84.08 \pm 6.86 \mathrm{Aa}$ & $85.67 \pm 4.72 \mathrm{Ab}$ & $87.44 \pm 5.56 \mathrm{Bb}$ \\
\hline
\end{tabular}

Different capital letters indicate difference between right and left sides in the same image.

Different small letters indicate difference of both techniques in the same side.

\section{Discussion}

Cone beam computed tomography images experienced substantial development in Dentistry during the past decade. It is now a diagnostic tool used worldwide as an auxiliary for complete diagnosis in many clinical challenges, allowing not only facial and maxillomandibular cross-sectioning, as well as 3D reconstructions ${ }^{13,14}$. Moreover, with the implementation of current hardware and software, DICOM images can now be formatted into MIP images, generating a multiplanar image, as in conventional radiographic films, such as panoramic, lateral, and frontal cephalograms.

Previous studies comparing conventional panoramic radiography with CBCT used axial, coronal, and or sagittal sections ${ }^{5,7}$, 3D images ${ }^{8,15}$, Dental CT images ${ }^{13,14,16}$, or reformatted curved panoramic sections ${ }^{17-19}$. No previous study could be found comparing conventional panoramic radiography with CBCT reformatted panoramic images in MIP mode.

The reproducibility of the examiners and methods was evaluated in several studies ${ }^{7,8,13,14,16-19}$. Despite the fact of the manual tracing of Puricelli's panorametry, which could aggregate a measurement bias, the ICC values found in the present research were excellent for both imaging methods.

Puricelli's panorametry differs from other methods, as it proposes the use of Cartesian lines to determine most anatomical points. There is minor examiner subjective influence in this graphimetric method $^{3,4,9-11}$. This may justify the high inter-examiner reproducibility of this proposed method.

Several studies compared measures acquired on panoramic radiography to dry skulls $2,5,6,8,16,17,20,21$, prototypes ${ }^{15}$, or proper acrylic models ${ }^{4}$. Others compared two images of the same patient ${ }^{13,18,19,22}$. Obviously, the panoramic image presents a projection or reconstruction of an arbitrary curved plane that anatomically does not exist. Hence, there will always be a degree of image adaptation. Studies comparing images of the same patient have problems setting a gold standard 1:1 pattern. Some authors say that CBCT develops images without clinically relevant magnification or distortion ${ }^{7,8,15}$. The evaluation of CBCT reformatted panoramic was not previously studied, as well its characteristics of magnification, distortion, and comparison with lab models or dry skulls. Studies like this might share similar limitations as those on conventional panoramic radiography, but possibly with greater reproducibility.

When comparing the conventional panoramic radiography to the $\mathrm{CBCT}$ reformatted panoramic, the total magnification found by this research had a mean value of $4.3 \%$, considering all measures. However, detailing this data reveals a heterogeneous pattern of magnification, presented at times as positive, and at other times as negative. Most of teeth angles, for example, were reduced in the conventional panoramic radiography, as well as some angular measures of the triangle composed by L2-L3-L4. Moreover, when the longest measurements of the images were compared, a significantly greater magnification was noticed, substantially larger near the mandible base on the horizontal aspect (11.5\%), and the posterior border of the ramus on the vertical aspect $(12 \%)$.

For molar angulations, on the other hand, significant lower values were observed for most measurements on the conventional panoramic radiography. As the mandible base is flatter in the CBCT reformatted image, the first molar is much more upright. As a result, the Long Axis of the Mandibular First Molar Teeth has a greater angle, which is more significant on the CD-CE line, closing to the $90^{\circ}$ mark. The exception would be its angle to $\mathrm{L} 2$, which is reduced in CBCT image. The L2 line is an oblique one, originating in the Condylar Point and extending to the Mental Foramen. Since the greatest magnification difference between the two imaging techniques is on the vertical aspect of the ramus, the L2 angle seems to present a more significant distortion than the first molar uprighting.

Comparing the right and left sides of images, and all measures considered, the right side of the conventional panoramic radiography consistently presented larger magnification. When considering skeletal measures (linear and angular), no significant difference could be observed between the right and left sides of the CBCT reformatted panoramic 
images. However, for the conventional panoramic radiography, all measurements of the right side showed significantly larger values in comparison to the left side, except for the angle L1-L4.

It is important to emphasize that no information about the asymmetric distortion or magnification on the conventional panoramic radiography could be found in literature. The most logical explanation to these results seems to be an issue during image acquisition, possibly of the conventional panoramic radiography, as it is the exam that presented the distortion. This issue could be related to problems with calibration and acquisition protocols of the equipment.

Further studies are necessary to evaluate the reliability of the CBCT reformatted panoramic as a reliable source for graphimetric methods.

\section{Conclusions}

Puricelli's panorametry presents excellent inter-examiner reproducibility. Conventional panoramic radiography presents magnified skeletal mandibular linear and angular measurements in Puricelli's panorametry when compared to CBCT reformatted panoramic images. The same does not happen in dental angular measurements.

\section{Resumo}

Objetivos: comparar a reprodutibilidade da panorametria de Puricelli em radiografias panorâmicas convencionais e reconstruções panorâmicas de TCFC, adquiridas em modo MIP, e as medidas angulares e lineares entre ambos os exames. Métodos: foram avaliados 54 pares de radiografias panorâmicas convencionais e reconstruções panorâmicas de TCFC. A panorametria foi traçada manualmente, em ambos os filmes, por três examinadores. As medidas lineares e angulares, dentárias e esqueléticas, originalmente propostas, foram tabuladas e comparadas entre os métodos de aquisição de imagem. A reprodutibilidade interexaminador foi testada pelo coeficiente de correlação intraclasse, e as diferenças entre as medidas de ambos os métodos foram analisadas através do teste $t$ de student. Resultados: a correlação interexaminador foi alta tanto para a radiografia panorâmica convencional quanto para a reconstrução panorâmica de TCFC $(0,86 \pm 0,07$ e 0,88 $\pm 0,07$ respectivamente). A magnificação total para a radiografia panorâmica, para as medidas estudadas, foi de $4,3 \%$, sendo maior no sentido vertical $(12 \%)$ e para a linha horizontal inferior $(11,5 \%)$ em comparação com as medidas angulares $(6,7 \%)$ e para a linha horizontal superior (1,9\%). A radiografia panorâmica convencional, em comparação a reconstrução panorâmica de TCFC, apresentou medidas angulares reduzidas. Conclusões: a panorametria de Puricelli apresenta alto grau de reprodutibilidade tanto em radiografias panorâmicas convencionais quanto em reconstruções panorâmicas de TCFC. As radiografias panorâmicas convencionais apresentam medidas angulares e lineares esqueléticas aumentadas e medidas angulares dentárias reduzidas, quando comparadas a reconstruções panorâmicas de TCFC. Radiografias panorâmicas convencionais apresentam, consistentemente, dimensões magnificadas no lado direito da imagem mandibular.

Palavras-chave: Tomografia Computadorizada de feixe cônico. Radiografia panorâmica. Mandíbula.

\section{References}

1. Puricelli E. Panorametry: suggestion of a method for mandibular measurements on panoramic radiographs. Head Face Med [online article] 2009 [accessed 2011 Jan 10]; 5(19). Available at: http://www.head-face-med.com/content/5/1/19.

2. Mozzo P, Procacci C, Tacconi A, Martini PT, Andreis IA. New volumetric CT machine for dental imaging based on the cone-beam technique: preliminary results. Eur Radiol 1998; 8(9):1558-64.

3. Mckee IA, Glover KE, Willanson PC, Lam EW, Heo G, Major PW. The effect of vertical and horizontal head positioning in panoramic radiography on mesiodistal tooth angulations. Angle Orthod 2001; 71:442-51.

4. Laster WS, Ludlow JB, Bailey LJ, Hershey HG. Accuracy of measurements of mandibular anatomy and prediction of asymmetry in panoramic radiographic images. Dentomaxillofacial Radiol 2005; 34:343-49.

5. Honey OB, Scarfe WC, Hilgers MJ, Klueber, K, Silveira AM, Haskell BS et al. Accuracy of cone-beam computed tomography imaging of the temporomandibular joint: comparisons with panoramic radiology and linear tomography. Am J Orthod Dentofacial Orthop 2007; 132(4):429-38.

6. Suomalainen A, Vehmas T, Kortesniemi M, Robinson S, Peltola J. Accuracy of linear measurements using dental cone beam and conventional multislice computed tomography. Dentomaxillofac Radiol 2008; 37(1):10-7.

7. Gracco A, Lombardo L, Cozzani M, Siciliani G. Quantitative cone-beam computed tomography evaluation of palatal bone thickness for orthodontic miniscrew placement. Am J Orthod Dentofacial Orthop 2008; 134(3):361-9.

8. Statemann SA, Huang JC, Maki K, Miller AJ, Hatcher DC. Comparison of cone beam computed tomography imaging with physical measures. Dentomaxillofac Radiol 2008; 37(2):80-93.

9. Ramesh A, Tyndall DA, Ludlow JB. Evaluation of a new digital panoramic system: a comparison with film. Dentomaxillofac Radiol 2001; 30(2):98-100.

10. Stramotas S, Geenty JP, Petocz P, Darendeliler MA. Accuracy of linear and angular measurements on panoramic radiographs taken at various positions in vitro. Eur J Radiol 2002; 24(1):43-52

11. Uthman AT. Retromolar Space analysis in relation to selected linear and angular measurements for an Iraqi sample. Oral Surg Oral Med Oral Pathol Oral Radiol Endod 2007; 104(4):e76-e82.

12. Puricelli E. Proposta de Metodologia para Traçado do Maxilar Inferior em Radiografia Panorâmica: Panorametria. Ortodon Gaúcha 2004; 8(2):4-10.

13. Nakagawa Y, Kobayashi K, Ishii H, Mishima H, Ishii K, Asada K, et al. Preoperative application of limited cone beam computerized tomography as an assessment tool before minor oral surgery. Int J Oral Maxillofac Surg 2002; 31(3):322-26. 
14. Guerrero ME, Jacobs R, Loubele M, Schutyser F, Suetens P, van Steenberghe D. State-of-the-art on cone beam CT imaging for preoperative planning of implant placement. Clin Oral Investig 2006; 10(1):1-7.

15. Lagravere MO, Carey J, Ben-Zvi M, Packota GV, Major PW. Effect of object location on the density measurement and hounsfield conversion in a Newton $3 \mathrm{G}$ cone beam computed tomography unit. Dentomaxillofac Radiol 2008; 37(6):3058.

16. Mol A, Balasundaram, A. In vitro cone beam computed tomography imaging of periodontal bone. Dentomaxillofac Radiol 2008; 37(6):319-24.

17. Ludlow JB, Laster WS, See M, Bailey LJ, Hershey HG. Accuracy of measurements of mandibular anatomy in cone beam computed tomography images. Oral Surg Oral Med Oral Pathol Oral Radiol Endod 2007; 103(4):534-42.

18. Tantanapornkul W, Okouchi K, Fujiwara Y, Yamashiro M, Maruoka Y, Ohbayashi N, et al. Comparative study of cone-beam computed tomography and conventional panoramic radiography in assessing the topographic relationship between the mandibular canal and impacted third molars. Oral Surg Oral Med Oral Pathol Oral Radiol Endod 2007; 103(2):253-9.

19. Angelopoulos C, Thomas SL, Hechler S, Parissis N, Hlavacek M. Comparison between digital panoramic radiography and cone-beam computed tomography for the identification of the mandibular canal as part of presurgical dental implant assessment. J Oral Maxillofac Surg 2008; 66(10):2130-5.

20. Moshiri M, Scarfe WC, Hilgers ML, Scheetz JP, Siveira AM, Farman AG. Accuracy of linear measurements from imaging plate and lateral cephalometric images derived from cone-beam computed tomography. Am J Orthod Dentofacial Orthop 2007; 132(4):550-60.

21. Loubele M, Jacobs R, Maes F, Denis K, White S, Coudyzer $\mathrm{W}$, et al. Image quality vs radiation dose of four cone beam computed tomography scanners. Dentomaxillofac Radiol 2008; 37(6):309-18.

22. Dannewitz B, Hassfeld S, Eickholz P, Mühling J. Effect of dose reduction in digital dental panoramic radiography on image quality. Dentomaxillofac Radiol 2002; 31(1):50-5.

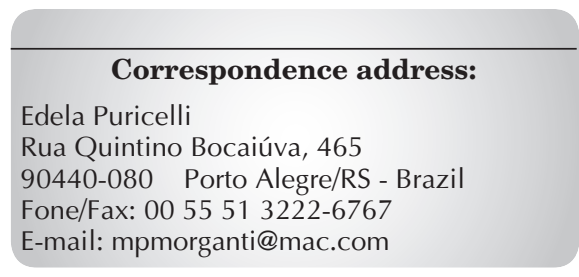

Recebido: 27/10/2012. Aceito: 03/04/2013. 